\title{
Risk of Reulceration and Reamputation after Minor Lower Extremity Amputation in Type 2 Diabetes: Systematic Review/Meta Analysis
}

\author{
MOHAMED A. KHALFALLA, M.D.*; MOHAMED E. FAKHR, M.D.** and AMMAR M. ABDALLAH, M.Sc.* \\ The Departments of General Surgery* and Vascular Surgery**, Faculty of Medicine, Ain Shams University
}

\begin{abstract}
Background: Diabetes is one of the most common chronic diseases in the world. The incidence of diabetes has increased steadily in recent years. Type 2 diabetes mellitus has reached epidemic proportions, affecting 56 million people in Europe ( i.e., $8.5 \%$ of the adult population).

Aim of Study: To establish, through the available literature the risk of re-ulceration, re-amputation in diabetic patients following minor lower limb extremity amputation.

Patients and Methods: The following electronic databases were searched up to 2019: PubMed, Google Scholar search engine, Cochrane database of systematic reviews, EMBASE and Science Direct, Wiley Online Library, The Journal of Ankle and Foot Surgery and Clinical Key database searching keywords and terms listed below: "Diabetic foot; Mortality; Toe amputation, Ulcers diabetic foot, Mid-foot amputation, Minor amputation, Peripheral vascular disease".

Results: In our meta-analysis, risk factors for the recurrence of DFUs included male gender, smoking, long duration of diabetes, long duration of past DFUs, plantar ulcers, PAD, and DPN. Also significant differences were found in age. On the other hand there was no relation between BMI and recurrence of DFUs.

Conclusion: The results of this meta-analysis showed that gender, smoking, duration of diabetes, BMI and hypertension were risk factors for DFU recurrence. By identifying these factors, health care staff could focus on the identified risk factors for the recurrence; hence, patients with a relatively higher risk of DFU recurrence could be treated in a more timely manner.
\end{abstract}

Key Words: Reulceration-Reamputation-Type 2 diabetes.

\section{Introduction}

THE natural history of diabetic neuropathy remains unclear, the late squeals of the disease include foot ulceration and, in the worst scenario, amputation [ 1]. According to community-based studies from North America and European countries, the annual

Correspondence to: Dr. Ammar M.

Abdallah,E-Mail: ammar.

Abrno.. 1110 m mail nom incidence of diabetic foot ulcers ranges from $0.6 \%$ to $2.2 \%$ [2]. It has been estimated that diabetes and its comorbidities account for $50 \%$ of the lower extremity amputations performed worldwide [3], and an estimated $85 \%$ of all diabetes-related amputations are preceded by a foot ulcer [4].

A Diabetic Foot Ulcer (DFU) is the most common cause of non-traumatic Lower-Extremity Amputations (LEAs) associated with diabetes. It not only causes great physical and mental pain in the patients, but is also a considerable financial burden on the patients' families and society as a whole. Toe amputation has the highest incidence among diabetic LEAs. Many epidemiological reports have published data regarding the incidences of amputation and mortality after LEAs [5].

Neuropathy, foot ulceration and, in the worst cases, amputation, lead to limited joint mobility in $30 \%$ to $40 \%$ of diabetic patients, especially in the ankle joint and first metatarsophalangeal joint [6]. Joint impairment can lead to functional gait variations, and their severitydepends on the extent of the neuropathy, ulcers, and level of amputation

[7]. Peripheral neuropathy, high-pressure areas on the sole of the foot, prolonged activity limited joint mobility, and foot deformity have been linked to the development of foot ulcerations [8], the most common component in the causal pathway to limb amputation in people with diabetes [9]. In the case of partial foot amputations, disruption of normal foot biomechanics probably increases existing areas of high pressure and the risk of ulceration [10].

The big toe plays an important role in foot biomechanics. During walking, it poses twice the total pressure of the other four toes [11]. Since the great toe is passively dorsi-flexed, the longitudinal 
arch of the foot is raised, the rearfoot supinated, the leg externally rotated, and the plantar aponeurosis tensed [12]. This is called windlass mechanism and is of great importance since it tenses the plantar fascia thus forming a rigid lever of the foot for push-off [9]. If the mechanism is altered, the timing and effectiveness of push-off would be affected. Therefore, great toe amputation will change intensely in foot biomechanics.

\section{Definition and classification of amputations:}

LEA was defined as the partial or total resection of the lower limb, through one or more bone structures and perpendicular to the longitudinal axis of the limb [13].

\section{There were two types of amputation:}

1- Major amputation was defined as being above the ankle (below-knee and above-knee).

2- Minor amputation as being limited to the foot ( from digital to Syme) [14].

\section{Re-amputation:}

Re-amputation was defined as the second LEA performed on the same person. The re-amputations considered were those performed at the ipsilateral level and on the same or a superior anatomical plane, or at the contralateral level. Surgical revision of the stump was not considered as an amputation

[15].

\section{Aim of the study:}

This study seeks to establish, through the available literature the risk of re-ulceration, reamputation in diabetic patients following minor lower limb extremity amputation.

\section{Patients and Methods}

\section{Literature search strategy:}

The following electronic databases were searched up to 2019: PubMed, Google Scholar search engine, Cochrane database of systematic reviews, EMBASE and Science Direct, Wiley Online Library, the Journal of Ankle and Foot Surgery and Clinical Key database searching keywords and terms listed below: "Diabetic foot; Mortality; Toe amputation, Ulcers diabetic foot, Mid-foot amputation, Minor amputation, Peripheral vascular disease".

Also full copies of articles of available medical journals and other published studies identified by the search, considered to meet the inclusion criteria, based on their title, abstract and subject descriptors, were obtained for data synthesis.

\section{Types of participants:}

This review considered all studies that involved type 2 diabetic patients undergoing non-traumatic minor LEAs.

\section{Types of interventions:}

Interventions of interest included those related to clinical outcomes of minor LEAs in patients with type 2 diabetes.

\section{Types of outcome measures:}

The primary outcome was reviewing clinical outcomes of minor LEAs in patients with type 2 diabetes and secondary outcome to be included was to determine the predictors for re-ulceration, re-amputation and mortality.

\section{Study inclusion and exclusion criteria:}

Studies were included if the following criteria were met: (A) Diabetic patients with healed foot ulcerations, (B) Case-control study or cohort study, (C) Comparison groups of recurrence and nonrecurrence, (D) Data on the risk factors for recurrence of DFUs reported as Odds Ratios (ORs) with 95\% confidence intervals (95\% CI), and (E) English or Chinese article. Editorials, reviews, letters, and comments were excluded from this analysis.

\section{Data abstraction and quality appraisal:}

A data extraction form was designed for the included studies. The following data were independently extracted by one researcher: First author, year of publication, location of study, type of study design, population size (recurrence/non-recurrence), sample ages, follow-up time, and risk factors. We also contacted the authors about unclear or missing information when necessary.

The methodological quality of included studies was independently assessed using the validated Newcastle-Ottawa Scale (NOS). The NOS is based on an accumulative score in each of three categories: Selection, comparability, and exposure or outcome. The NOS scores range between 0 and 9 stars. Studies with 6 to 9 stars were considered to be at low Risk of Bias (ROB), studies with 4 to 5 stars were considered to be at medium ROB, and studies with 1 to 3 stars were considered to be at high ROB. Two researchers independently performed the quality assessment for included studies, and disagreement was resolved by discussion.

\section{Results}

The seventeen studies included in the systematic review and meta-analysis was retrospective cohort studies published between 2006 and 2018. A total 
of 3022 patients were involved and mean ranged from 51.73 to 72.6 years. Three studies failed to provide a mean age for participants, the characteristics of the included studies are listed in ( Table 1).

Table (1): Characteristics of the included studies $(\mathrm{N}=17)$.

\begin{tabular}{|c|c|c|c|c|c|c|}
\hline \multirow{2}{*}{ Papers } & \multirow{2}{*}{$\begin{array}{l}\text { Number } \\
\text { of } \\
\text { patients }\end{array}$} & Male & \multicolumn{2}{|c|}{ Female } & \multirow{2}{*}{$\begin{array}{c}\text { Mean } \\
\text { of } \\
\text { age }\end{array}$} & \multirow{2}{*}{$\begin{array}{l}\text { Average } \\
\text { follow-up } \\
\text { duration } \\
\text { (month) }\end{array}$} \\
\hline & & No. $\%$ & No. & $\%$ & & \\
\hline - Pollard et al., [16] & 101 & 7877.2 & 23 & 22.8 & 64.3 & 25.2 \\
\hline - Blume et al., [17] & 91 & 5964.8 & 32 & 35.2 & 62 & 12 \\
\hline - Krause et al., [18] & 65 & $42 \quad 64.6$ & 23 & 35.4 & 57.9 & 28.8 \\
\hline - Younger et al., [19] & 68 & $55 \quad 80.9$ & 13 & 19.1 & NR & NR \\
\hline - Landry et al., [20] & 62 & 59.7 & 25 & 40.3 & 60.7 & NR \\
\hline - Terashi et al., [21 ] & 11 & $\begin{array}{ll}8 & 72.7\end{array}$ & 3 & 27.3 & 71 & 20 \\
\hline - Brown et al., [22] & 21 & NR NR & NR & NR & 53.8 & 60 \\
\hline $\begin{array}{l}\text { - McCallum et al., } \\
{[23]}\end{array}$ & 12 & 1083.3 & 2 & 16.7 & 52 & NR \\
\hline - Dubsk'y et al., [24] & 73 & $60 \quad 82.1$ & 13 & 17.8 & NR & 36 \\
\hline - O'Brien et al., [25] & 1205 & 80466.7 & 401 & 33.3 & 65 & 1 \\
\hline - Qian et al., [26] & 108 & NR NR & NR & NR & 68 & 12 \\
\hline $\begin{array}{l}\text { Yue-Jie and } \\
\text { Xi-Wen, [5] }\end{array}$ & 245 & 14559.2 & 100 & 40.8 & NR & 36 \\
\hline - Hu et al., [27] & 231 & 10143.7 & 130 & 56.3 & 58.3 & 36 \\
\hline - Chang et al., [28] & 282 & 17562.1 & 107 & 37.9 & 65 & 37.14 \\
\hline - Khalifa, [29] & 93 & $44 \quad 47.3$ & 49 & 52.7 & 51.73 & 24 \\
\hline - Mo et al., [30] & 189 & 11862.4 & 71 & 37.6 & 66.60 & 44.83 \\
\hline - Xie et al., [31 ] & 165 & $87 \quad 52.7$ & 78 & 47.3 & 72.6 & 24 \\
\hline
\end{tabular}

NR: No Report.

Seven of the 17 studies reported specific data on reulceration. The reulceration rate ranged from $0 \%$ to $75.9 \%$. A total of 533 any level reulceration ( $31.6 \%$ ) were reported after 1686 TMAs, and seven of the 17 studies reported specific data on reamputation. The reamputation rate ranged from $0 \%$ to $30.7 \%$. A total of 116 any level reamputations ( $6.9 \%$ ) were reported after 1686 TMAs.

Table (2): Characteristics of the included studies $(\mathrm{N}=17)$.

\begin{tabular}{|c|c|c|c|c|c|c|c|}
\hline \multirow[t]{2}{*}{ Papers } & \multirow[t]{2}{*}{$\begin{array}{l}\text { Number } \\
\text { of } \\
\text { patients }\end{array}$} & \multicolumn{2}{|c|}{$\begin{array}{c}\text { Number of } \\
\text { patient } \\
\text { had risk } \\
\text { factor }\end{array}$} & \multicolumn{2}{|c|}{$\begin{array}{l}\text { Reul- } \\
\text { ceration }\end{array}$} & \multicolumn{2}{|c|}{$\begin{array}{c}\text { Reampu- } \\
\text { tation }\end{array}$} \\
\hline & & No. & $\%$ & No. & $\%$ & No. & $\%$ \\
\hline - Pollard et al., [16] & 101 & 31 & 30.7 & 0 & 0.0 & 31 & 30.7 \\
\hline - Blume et al., [17] & 91 & 48 & 52.7 & 25 & 27.5 & 23 & 25.3 \\
\hline - Krause et al., [18] & 65 & 0 & 0.0 & NR & NR & NR & NR \\
\hline - Younger et al., [19] & 68 & 0 & 0.0 & NR & NR & NR & NR \\
\hline - Landry et al., [20] & 62 & 0 & 0.0 & NR & NR & NR & NR \\
\hline - Terashi et al., [21] & 11 & 1 & 9.1 & 1 & 9.1 & 0 & 0.0 \\
\hline - Brown et al., [22] & 21 & 4 & 19.0 & 2 & 9.5 & 2 & 9.5 \\
\hline - McCallum et al., [23] & 12 & 2 & 16.7 & 1 & 8.3 & 1 & 8.3 \\
\hline - Dubsky' et al., [24] & 73 & NR & NR & NR & NR & NR & NR \\
\hline - O'Brien et al., [25] & 1205 & 318 & 26.4 & 318 & 26.4 & 0 & 0.0 \\
\hline - Qian et al., [26] & 108 & NR & NR & NR & NR & NR & NR \\
\hline - Hu et al., [27] & 231 & NR & NR & NR & NR & NR & NR \\
\hline $\begin{array}{l}\text { - Yue-Jie and Xi-Wen, } \\
\text { [5] }\end{array}$ & 245 & 245 & 100.0 & 186 & 75.9 & 59 & 24.1 \\
\hline - Chang et al., [28] & 282 & NR & NR & NR & NR & NR & NR \\
\hline - Khalifa, [29] & 93 & NR & NR & NR & NR & NR & NR \\
\hline - Mo et al., [30] & 189 & NR & NR & NR & NR & NR & NR \\
\hline - Xie et al., [31 ] & 165 & NR & NR & NR & NR & NR & NR \\
\hline Total & 3022 & 1039 & 34.38 & 533 & 31.6 & 116 & 6.9 \\
\hline
\end{tabular}

The following table shows that age is mentioned as a risk factor in three of the eight Papers by $37.5 \%$, as the sex factor was mentioned in six Papers by $75 \%$, as the smoking factor was mentioned in five Papers by $62.5 \%$, as the BMI factor was mentioned in three Papers by $37.5 \%$, as the duration of DM factor was mentioned in three Papers by $37.5 \%$, as the duration of past diabetic foot ulcer factor was mentioned in one Papers by $12.5 \%$ plantar ulcer is mentioned as a risk factor in three of the one Papers by $12.5 \%$.

Table (3): Meta-analysis of demographic factors for the recurrence of DFUs.

\begin{tabular}{|c|c|c|c|c|c|c|c|}
\hline \multirow[b]{2}{*}{ Papers } & \multicolumn{7}{|c|}{ Risk factors } \\
\hline & \multicolumn{2}{|c|}{ Age Sex } & \multicolumn{3}{|c|}{$\begin{array}{l}\text { S mok Bur a tion } \\
\text { ing of DM }\end{array}$} & \multirow{2}{*}{$\begin{array}{l}\text { Duration } \\
\text { of past } \\
\text { diabetic } \\
\text { foot ulcer }\end{array}$} & \multirow{2}{*}{$\begin{array}{l}\begin{array}{c}\text { Plantar } \\
\text { ulcer }\end{array} \\
\text { Yes }\end{array}$} \\
\hline $\begin{array}{l}\text { - Dubsk'y et al., } \\
\text { [24] }\end{array}$ & No & Yes & Yes & No & No & & \\
\hline $\begin{array}{l}\text { - Qian et al., } \\
\text { [26] }\end{array}$ & No & No & No & No & No & No & No \\
\hline - Hu et al., [27] & Yes & Yes & No & Yes & Yes & No & No \\
\hline $\begin{array}{l}\text { Yue-Jie and } \\
\text { Xi-Wen, [5] }\end{array}$ & Yes & No & No & No & No & No & No \\
\hline $\begin{array}{l}\text { - Chang et al., } \\
{[\mathbf{2 8}]}\end{array}$ & Yes & Yes & Yes & Yes & Yes & Yes & No \\
\hline - Khalifa, [29] & No & Yes & Yes & Yes & Yes & No & No \\
\hline $\begin{array}{l}\text { - Mo et al., } \\
{[\mathbf{3 0}]}\end{array}$ & & Yes & Yes & No & No & No & No \\
\hline $\begin{array}{l}\text { - Xie et al., } \\
\text { [31 ] }\end{array}$ & No & Yes & Yes & No & No & No & No \\
\hline \multicolumn{8}{|l|}{ - Total: } \\
\hline No. & 3 & 6 & 5 & 3 & 3 & 1 & 1 \\
\hline$\%$ & 37.5 & 75.0 & 62.50 & 37.5 & 37.5 & 12.5 & 12.5 \\
\hline
\end{tabular}

The following table shows that the peripheral artery disease factor was mentioned in five Papers by $62.5 \%$, as the diabetic peripheral neuropathy factor was mentioned in two Papers by $25.0 \%$, as the diabetic nephropathy factor was mentioned in four Papers by $50.0 \%$, as the diabetic retinopathy factor was mentioned in four Papers by $50.0 \%$, as the HTN factor was mentioned in four Papers by $50.0 \%$ and the total cholesterol factor was mentioned in two Papers by $25.0 \%$.

Two studies reported the relationship between age and the risk of DFU recurrence. However, obvious heterogeneity was found among the included studies $(t=6.283, p=0.000)$.

Sex studies that included a total of 1036 patients provided eligible data for demonstrating the relationship between gender and DFU recurrence. The pooled results showed that males had a higher risk of developing DFU recurrence than females ${ }_{x} 2=$ $45.374, p=0.000$ ). 
Table (4): Meta-analysis of clinical factors for the recurrence of DFUs.

\begin{tabular}{|c|c|c|c|c|c|c|}
\hline \multirow[b]{2}{*}{ Papers } & \multicolumn{6}{|c|}{ Risk factors } \\
\hline & $\begin{array}{l}\text { Peri- } \\
\text { pheral } \\
\text { artery } \\
\text { disease }\end{array}$ & $\begin{array}{c}\text { Diabetic } \\
\text { Peripheral } \\
\text { neuro- } \\
\text { pathy }\end{array}$ & $\begin{array}{l}\text { Dia- } \\
\text { betic } \\
\text { pathy }\end{array}$ & $\begin{array}{l}\text { Dia- } \\
\text { betic } \\
\text { pathy }\end{array}$ & HTN & $\begin{array}{c}\text { Total } \\
\text { choles- } \\
\text { terol }\end{array}$ \\
\hline $\begin{array}{l}\text { - Dubsk'y et al., } \\
\text { [24] }\end{array}$ & Yes & No & Yes & No & No & No \\
\hline - Qian et al., [26] & No & No & No & No & No & Yes \\
\hline - Hu et al., [27] & No & No & No & Yes & No & No \\
\hline $\begin{array}{l}\text { Yue-Jie and } \\
\text { Xi-Wen, [5] }\end{array}$ & No & No & No & No & No & No \\
\hline $\begin{array}{l}\text { - Chang et al., } \\
\text { [28] }\end{array}$ & Yes & No & Yes & Yes & Yes & No \\
\hline - Khalifa, [29] & Yes & Yes & Yes & Yes & Yes & Yes \\
\hline - Mo et al., [30] & Yes & Yes & Yes & Yes & Yes & No \\
\hline - Xie et al., [31 ] & Yes & No & No & No & Yes & No \\
\hline \multicolumn{7}{|l|}{ - Total: } \\
\hline No. & 5 & 2 & 4 & 4 & 4 & 2 \\
\hline$\%$ & 62.5 & 25.0 & 50.0 & 50.0 & 50.0 & 25.0 \\
\hline
\end{tabular}

Table (5): Comparison between 2 Paper regarding age.

\begin{tabular}{|c|c|c|c|c|c|}
\hline \multirow{2}{*}{ Papers } & \multicolumn{2}{|c|}{ Age } & \multirow{2}{*}{$\begin{array}{c}\text { Test } \\
\text { value }\end{array}$} & \multirow{2}{*}{$\begin{array}{c}p- \\
\text { value }\end{array}$} & \multirow{2}{*}{ Sig. } \\
\hline & Mean & SD & & & \\
\hline $\begin{array}{l}\text { Hu et al., [27] } \\
\text { Chang et al., [28] }\end{array}$ & $\begin{array}{l}58.3 \\
65\end{array}$ & $\begin{array}{l}10.2 \\
0\end{array}$ & 6.283 & 0.000 & HS \\
\hline
\end{tabular}

Table (6): Comparison between 6 Paper regarding sex.

\begin{tabular}{|c|c|c|c|c|c|c|c|}
\hline \multirow{3}{*}{ Papers } & \multicolumn{4}{|c|}{ Sex } & \multirow{3}{*}{$\begin{array}{c}\text { Test } \\
\text { value }\end{array}$} & \multirow{3}{*}{$\begin{array}{c}p- \\
\text { value }\end{array}$} & \multirow{3}{*}{ Sig. } \\
\hline & \multicolumn{2}{|c|}{ Male } & \multicolumn{2}{|c|}{ Female } & & & \\
\hline & No. & $\%$ & No. & $\%$ & & & \\
\hline Dubsk'y et al., [24] & 60 & 10.26 & 13 & 2.90 & 45.374 & 0.000 & HS \\
\hline Hu et al., [27] & 101 & 17.26 & 130 & 29.02 & & & \\
\hline Chang et al., [28] & 175 & 29.91 & 107 & 23.88 & & & \\
\hline Khalifa, [29] & 44 & 7.52 & 49 & 10.94 & & & \\
\hline Mo et al., [30] & 118 & 20.17 & 71 & 15.85 & & & \\
\hline Xie et al., [31 ] & 87 & 14.87 & 78 & 17.41 & & & \\
\hline Total & 585 & 100.0 & 448 & 100.0 & & & \\
\hline
\end{tabular}

Table (7): Comparison between 5 Paper regarding smoking.

\begin{tabular}{lllllllll}
\hline & \multicolumn{3}{c}{ Smoking } & & & \\
\cline { 2 - 5 } & \multicolumn{3}{c}{ Recurrence } & \multicolumn{2}{c}{$\begin{array}{c}\text { Non } \\
\text { recurrence }\end{array}$} & $\begin{array}{c}\text { Test } \\
\text { value }\end{array}$ & $\begin{array}{c}p \text { - } \\
\text { value }\end{array}$ & Sig. \\
\cline { 2 - 6 } & No. & $\%$ & No. & $\%$ & & & \\
\hline Dubsk'y et al., [24] & 4 & 3.1 & 4 & 3.1 & 12.984 & 0.011 & S \\
Chang et al., [28] & 41 & 31.5 & 54 & 41.9 & & & \\
Khalifa, [29] & 25 & 19.2 & 7 & 5.4 & & & \\
Mo et al., [30] & 38 & 29.2 & 35 & 27.1 & & & \\
Xie et al., [31 ] & 22 & 16.9 & 29 & 22.5 & & & \\
\hline Total & 130 & 100 & 129 & 100.0 & & & \\
\hline
\end{tabular}

Five studies that included a total of 802 patients provided available data on the association between smoking and DFU recurrence. The pooled results showed that smoking was associated with an in creased incidence of DFU recurrence $\left(\chi^{2}=12.984, p\right.$ $=0.011$ ).

Table (8): Comparison between 3 Paper regarding BMI.

\begin{tabular}{|c|c|c|c|c|c|}
\hline & \multicolumn{2}{|c|}{ BMI } & \multirow{2}{*}{$\begin{array}{l}\text { Test } \\
\text { value }\end{array}$} & \multirow{2}{*}{$\begin{array}{c}p- \\
\text { value }\end{array}$} & \multirow{2}{*}{ Sig } \\
\hline & $\begin{array}{l}\text { Recurrence } \\
\text { Mean } \pm\end{array}$ & $\begin{array}{l}\text { Non recurrence } \\
\text { Mean } \pm \text { SD }\end{array}$ & & & \\
\hline Hu et al., [27] & $23.3 \pm 2.8$ & $22.6 \pm 2.3$ & -2.249 & 0.025 & $\mathrm{~S}$ \\
\hline Chang et al., [28] & $23.73 \pm 3.26$ & $23.81 \pm 3.01$ & 0.171 & 0.864 & NS \\
\hline Khalifa, [29] & $29.63 \pm 4.51$ & $31.54 \pm 3.97$ & 2.081 & 0.042 & $\mathrm{~S}$ \\
\hline Total & $76.66 \pm 10.57$ & $77.95 \pm 9.28$ & 1.552 & 0.121 & NS \\
\hline
\end{tabular}

Three studies available data were provided on the relationship between BMI and DFU recurrence. However, moderate homogeneity was found among the included studies $(t=1.552, p=0.121)$.

Table (9): Comparison between 3 Paper regarding duration of DM.

\begin{tabular}{lllll}
\hline & \multicolumn{3}{c}{ Duration of DM } & \\
\cline { 2 - 3 } & $\begin{array}{c}\text { Recurrence } \\
\text { Mean } \pm\end{array}$ & $\begin{array}{c}\text { Non recurrence } \\
\text { Mean } \pm \text { SD }\end{array}$ & $\begin{array}{c}\text { Test } \\
\text { value }\end{array}$ & $\begin{array}{c}p \text { - Sig. } \\
\text { value }\end{array}$ \\
\hline Hu et al., [27] & $13.5 \pm 5.7$ & $7.5 \pm 3.2$ & -9.928 & $0.000 \mathrm{HS}$ \\
Chang et al., [28] & $11.74 \pm 6.53$ & $9.77 \pm 7.02$ & -2.292 & $0.022 \mathrm{~S}$ \\
Khalifa, [29] & $13.76 \pm 5.42$ & $8.46 \pm 3.21$ & -5.303 & $0.000 \mathrm{HS}$ \\
\hline Total & $39 \pm 17.65$ & $25.73 \pm 13.43$ & -10.353 & $0.000 \mathrm{HS}$ \\
\hline
\end{tabular}

The pooled results for 3 studies showed that that duration of DM was associated with an increased incidence of DFU recurrence $(t=10.353, p$ $=0.000$ ).

Table (10): Comparison between 5 paper regarding peripheral artery disease.

\begin{tabular}{|c|c|c|c|c|c|c|c|}
\hline \multirow{3}{*}{ Papers } & \multicolumn{4}{|c|}{ Peripheral artery disease } & \multirow{3}{*}{$\begin{array}{c}\text { Test } \\
\text { value }\end{array}$} & \multirow{3}{*}{$\begin{array}{c}p- \\
\text { value }\end{array}$} & \multirow{3}{*}{ Sig. } \\
\hline & \multicolumn{2}{|c|}{ Recurrence } & \multicolumn{2}{|c|}{$\begin{array}{c}\text { Non } \\
\text { recurrence }\end{array}$} & & & \\
\hline & No. & $\%$ & No. & $\%$ & & & \\
\hline Dubsk'y et al., [24] & 9 & 4.5 & 7 & 2.6 & 22.766 & 0.000 & HS \\
\hline Chang et al., [28] & 69 & 34.2 & 131 & 48.0 & & & \\
\hline Khalifa, [29] & 18 & 8.9 & 7 & 2.6 & & & \\
\hline Mo et al., [30] & 65 & 32.2 & 57 & 20.9 & & & \\
\hline Xie et al., [31] & 41 & 20.3 & 71 & 26.0 & & & \\
\hline Total & 202 & 100.0 & 273 & 100.0 & & & \\
\hline
\end{tabular}

Five studies provided extractable data to analyse the association between the risk of DFU recurrence and PAD. The fixed effects model showed that patients with PAD were at a significant risk of DFU recurrence $\left(\chi^{2}=22.766, p=0.000\right)$.

Two studies that included a total of 255 patients provided available data on the association between DPN and DFU recurrence. However, no significant difference was found between the combined estimates. 
Table (11): Comparison between two Paper regarding diabetic peripheral neuropathy.

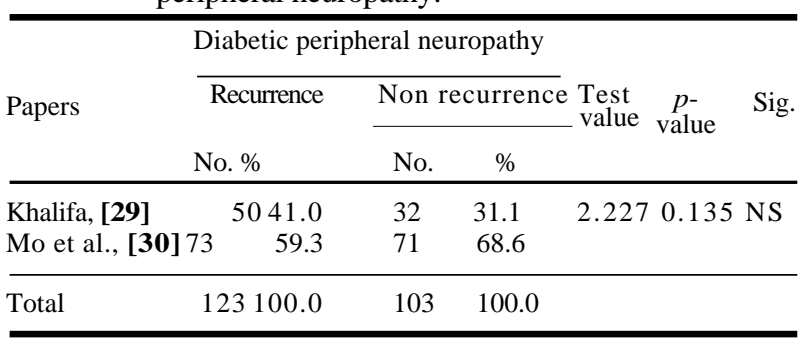

Table (12): Comparison between 4 Paper regarding diabetic nephropathy.

\begin{tabular}{|c|c|c|c|c|c|}
\hline \multirow{3}{*}{ Papers } & \multicolumn{3}{|c|}{ Diabetic nephropathy } & \multirow{3}{*}{$\begin{array}{c}\text { Test } \quad p- \\
- \text { value value }\end{array}$} & \multirow{3}{*}{ Sig. } \\
\hline & Recurrence & Non & currence & & \\
\hline & No. $\%$ & \multicolumn{2}{|c|}{ No. $\%$} & & \\
\hline Dubsk'y et al., [24] & 5.2 & 3 & 2.7 & 4.5290 .209 & NS \\
\hline Chang et al., [28] & 3738.1 & 58 & 51.8 & & \\
\hline Khalifa, [29] & 1212.4 & 9 & 8.0 & & \\
\hline Mo et al., [30] & 4344.3 & 42 & 37.5 & & \\
\hline Total & 97100.0 & 11 & 100.0 & & \\
\hline
\end{tabular}

Four studies that included a total of 637 patients provided available data on the association between DN and DFU recurrence. However, no significant difference was found between the combined estimates.

Table (13): Comparison between 3 Paper regarding diabetic retinopathy.

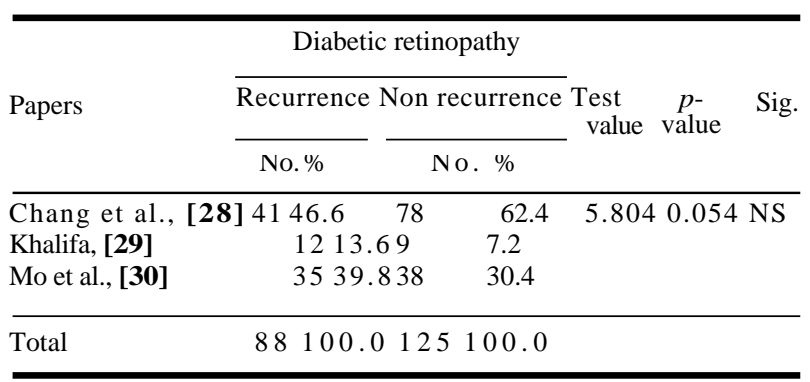

Three studies that included a total of 564 patients provided available data on the association between DR and DFU recurrence. However, no significant difference was found between the combined estimates.

Table (14): Comparison between 4 Paper hypertension.

\begin{tabular}{|c|c|c|c|c|c|}
\hline \multirow{3}{*}{ Papers } & \multicolumn{3}{|c|}{ Hypertension } & \multirow{3}{*}{\multicolumn{2}{|c|}{$\begin{array}{c}p- \\
\text { value }\end{array}$}} \\
\hline & \multirow{2}{*}{$\begin{array}{l}\text { Recurrence } \\
\text { No. } \%\end{array}$} & \multicolumn{2}{|c|}{$\overline{\text { Non recurrence }}$} & & \\
\hline & & \multicolumn{2}{|c|}{ No. \% } & & \\
\hline \multicolumn{2}{|c|}{ Chang et al., [28] 5233.3} & 86 & 43.9 & \multirow{4}{*}{\multicolumn{2}{|c|}{$11.9220 .007 \mathrm{HS}$}} \\
\hline Khalifa, [29] & $41 \quad 26.3$ & 26 & 13.3 & & \\
\hline Mo et al., [30] & 4629.5 & 53 & 27.0 & & \\
\hline Xie et al., [31] & $17 \quad 10.9$ & 31 & 15.8 & & \\
\hline \multicolumn{2}{|l|}{ Total } & & 156100 & 0.019 & 6100.0 \\
\hline
\end{tabular}

Fourstudies that included a total of 729 patients provided available data on the association between Hypertension and DFU recurrence. However, highly significant difference was found between the combined estimates.

\section{Discussion}

Diabetic Foot Ulcers (DFUs) are one of the most serious complications in diabetic patients as they are perhaps the most common cause of diabetes-related hospitalization and may lead to amputation [32].

It is estimated that the annual risk of developing a DFU in diabetic patients ranges from $19 \%$ to $34 \%$. Approximately $40 \%$ of patients with DFUs experience a recurrence within 1 year after the ulcer has healed, nearly $60 \%$ within 3 years, and $65 \%$ within 5 years [32].

Recurrent foot ulcerations result from various factors that have adverse effects on patients' physiological condition, mental health, and social functioning. In addition, these recurrent ulcers increase the patient's medical burden because of long-term costs related to wound management. Hence, it is necessary to identify the risk factors of recurrent DFUs and provide evidence for their prevention [ 33]. So, the aim of this metanalysis was seeks to establish, through the available literature the risk of re-ulceration, re-amputation and mortality in diabetic patients following minor lower limb extremity amputation, and the impact of activities of daily living on clinical outcomes.

The seventeen studies included in the systematic review and Meta-analysis was retrospective cohort studies published between 2006 and 2018. A total of 3022 patients were involved and mean ranged from 51.73 to 72.6 years. Three studies failed to provide a mean age for participants.

Seven of the seventeen studies reported specific data on reulceration. The reulceration rate ranged from $0 \%$ to $75.9 \%$. A total of 533 any level reulceration $(31.6 \%)$ were reported after $1686 \mathrm{TMAs}$, and seven of the 17 studies reported specific data on reamputation. The reamputation rate ranged from $0 \%$ to $30.7 \%$. A total of 116 any level reamputations $(6.9 \%)$ were reported after 1686 TMAs.

In our metanalysis, age is mentioned as a risk factor in three of the eight Papers by $37.5 \%$, as the sex factor was mentioned in six Papers by $75 \%$, as the smoking factor was mentioned in five Papers by $62.5 \%$, as the BMI factor was mentioned in three Papers by $37.5 \%$, as the duration of DM 
factor was mentioned in three Papers by $37.5 \%$, as the duration of past diabetic foot ulcer factor was mentioned in one Papers by $12.5 \%$ plantar ulcer is mentioned as a risk factor in three of the one Papers by $12.5 \%$.

In our meta-analysis, risk factors for the recurrence of DFUs included male gender, smoking, long duration of diabetes, long duration of past DFUs, plantar ulcers, PAD, and DPN. Also significant differences were found in age. On the other hand there was no relation between BMI and recurrence of DFUs.

In our study, sex studies that included a total of 1036 patients Dubsk'y et al., [24], Hu et al., [27], Chang et al., [28], Khalifa [29], Mo et al., [30] and Xie et al., [31] provided eligible data for demonstrating the relationship between gender and DFU recurrence. The pooled results showed that males had a higher risk of developing DFU recurrence than females $\left(\mathrm{X}^{2}=45.374, p=0.000\right)$.

Meta-analysis results by Huang et al., [32] supports our results in showing that the risk of DFU recurrence in male patients was 1.38 times higher than that in female patients, which was consistent with the results of a previous study [34].

Our results showed that five studies Dubsk'y et al., [24], Chang et al., [28], Khalifa [29], Mo et al., [30] and Xie et al., [31] included a total of 802 patients provided available data on the association between smoking and DFU recurrence. The pooled results showed that smoking was associated with an increased incidence of DFU recurrence $\left(X_{2}=\right.$ 12.984, $p=0.011$ ).

Our result is consistent with these studies. Although several studies Dubsk'y et al., [24], Chang et al., [28], Mo et al., [30] and Waaijman et al., [35] reported that smoking was not a risk factor of DFU recurrence, these studies were limited in their small sample size, while our result was based on five studies according to previous studies, smoking affects the control of blood glucose in diabetic patients, which is closely related to the occurrence of DFUs. In addition, smoking can cause vasoconstriction and blood flow obstruction, leading to ischemia and affecting the repair of ulcers [36].

As shown in our study, three studies Hu et al., [ 27], Chang et al., [28] and Khalifa [29] were provided on the relationship between BMI and DFU recurrence. However, moderate homogeneity was found among the included studies $(t=1.552, p=0$. 121).
The pooled results for 3 studies $\mathrm{Hu}$ et al., [27], Chang et al., [28] and Khalifa [29] showed that that duration of DM was associated with an increased incidence of DFU recurrence ( $t=-10.353, p=0.000$ ).

Our study also found that, with the progression of diabetes, the risk of DFU recurrence increases with high statistical significance which is consistent with the studies of Qian et al., [26] and $\mathrm{Hu}$ et al., [ 27] but studies conducted by Chang et al., [28] and Khalifa [29] found that the duration of diabetes was not an independent risk factor for DFU recurrence; however, the authors did not give any explanation for this negative result.

As commonly acknowledged, PAD can cause abnormalities in the microcirculation of the foot, resulting in poor blood supply; hence, the recurrence rate of DFUs in patients with PAD is high [35].

Our study showed no significant differences between DFU and DPN. On the other hand, Huang et al., [32] metanalysis showed that DFU patients with DPN were at a higher risk of DFU recurrence unlike our results but was consistent with the results of a previous study by Connor and Mahdi [37]. DFU patients with DPN may experience feelings of abnormal temperature or pain sensations in their feet, and their perception of external stimuli will be weakened and easily damaged. Furthermore, sweat glands will be demineralized in case of autonomic neuropathy, which will make the skin on the foot dry, chapped, and prone to ulcers. In motor neuropathy, foot muscle atrophy leads to foot malformations, and foot compression imbalance is also prone to damage [38].

Our study lacked for the duration of past DFUs as a risk factor of DFU recurrence but Hung et al., [ 39] metanalysis showed that duration of past DFUs was a risk factor of DFU recurrence. This might be explained by Mai et al., [40] study which showed that the risk of recurrent ulcerations in patients with a DFU > 2 months at the first visit was 1.93 times higher than that in patients with a DFU $<2$ months, which was related to the delayed visit and the improper treatment of wounds in patients with DFUs, suggesting that early and proper treatment should be carried out in the care of DFU patients for preventing recurrent ulcerations.

\section{Conclusion:}

The results of this meta-analysis showed that gender, smoking, duration of diabetes, BMI and hypertension were risk factors for DFU recurrence. By identifying these factors, health care staff 
focus on the identified risk factors for the recurrence; hence, patients with a relatively higher risk of DFU recurrence could be treated in a more timely manner.

\section{References}

1- BOULTON A.J.: Lowering the risk of neuropathy, foot ulcers and amputations. Diabet. Med., 15 (4): S57-S59, 1998.

2- MOREY-VARGAS O.L. and SMITH S.A.: Be Smart: Strategies for foot care and prevention of foot complications in patients with diabetes. Prosthet. Orthot. Int., 39: 48-60, 2015.

3- MARKS R.M., LONG J.T. and EXTEN E.: Gait abnormality following amputation in diabetic patients. Foot Ankle Clin., 15: 501-7, 2010.

4- RASPOVIC A.: Gait characteristics of people with diabetes-related peripheral neuropathy, with and without a history of ulceration. Gait. Posture, 38: 723-8, 2013.

5- YUE-JIE C. and XI-WEN L.: Clinical outcomes of toe amputation in patients with type 2 diabetes in Tianjin, China; International Wound Journal ISSN 1742-4801: 2014.

6- FORMOSA C., GATT A. and CHOCKALINGAM N.: The importance of clinical biomechanical assessment of foot deformity and joint mobility in people living with type-2 diabetes within a primary care setting. Prim. Care Diabetes, 7: 45-50, 2013.

7- IRENE A. and MARCO G.: Does First Ray Amputation in Diabetic Patients Influence Gait and Quality of Life?; The Journal of Foot \& Ankle Surgery, 57: 44-51, 2018.

8- QUEBEDEAUX T.L., LAVERY L.A. and LAVERY D.C.: The development of foot deformities and ulcers after great toe amputation in diabetes. Diabetes Care, 19 (2): 165- 7, 1996.

9- CHOU S.W., CHENG H.Y., CHEN J.H., et al.: The role of the great toe in balance performance. Journal of Orthopaedic Research, 27: 549-54, 2009.

10- MOTAWEA M.: International Journal of Advancement Research: Impact of big toe amputation in biomechanics, 3 (12): 1224-8, 2015.

11- TANAKA T., HASHIMOTO N., NAKATA M., et al.: Analysis of toe pressures under the foot while dynamic standing on one foot in healthy subjects. J. Orthop. Sports Phys. Ther., 23: 188-93, 1996.

12- HICKS J.H.: The mechanism of the foot. II. The plantar aponeurosis and the arch. J. Anat., 88: 25-30, 1954.

13- KENNON B., LEESE G.P., COCHRANE L., et al.: Reduced incidence of lower-extremity amputations in people with diabetes in Scotland: A nationwide study, Diabetes Care, 35 (12): 2588-90, 2012.

14- ALMARAZ M.C., GONZÁLEZ-ROMERO S., BRAVO

M., et al.: Incidence of lower limb amputations in individuals with and without diabetes mellitus in Andalusia ( Spain) from 1998 to 2006, Diabetes Res. Clin. Pract., 95 (3): 399-405, 2012.

15- KANADE R., VAN DEURSEN R., BURTON J., et al.: Re-amputation occurrence in the diabetic population in
South Wales, UK. International wound journal, 4 (4): 344-52, 2007.

16- POLLARD J., HAMILTON G.A., RUSH S.M., et al.: Mortality and morbidity after transmetatarsal amputation: Retrospective review of 101 cases. J. Foot Ankle Surg., 45: 91-7, 2006.

17- BLUME P., SALONGA C., GARBALOSA J., et al.: Predictors for the healing of transmetatarsal amputations: Retrospective study of 91 amputations. Vascular, 15: 12633, 2007.

18- KRAUSE F.G., DeVRIES G., MEAKIN C., et al.: Outcome of transmetatarsal amputations in diabetics using antibiotic beads. Foot Ankle Int., 30: 486-93, 2009.

19- YOUNGER A.S., AWWAD M.A., KALLA T.P., et al.: Risk factors for failure of transmetatarsal amputation in diabetic patients: A cohort study. Foot Ankle Int., 30: 1177-82, 2009 .

20- LANDRY G.J., SILVERMAN D.A., LIEM T.K., et al.: Predictors of healing and functional outcome following transmetatarsal amputations. Arch. Surg., 146: 1005-9, 2011.

21- TERASHI H., KITANO I., TSUJI Y., et al.: A modified transmetatarsal amputation. J. Foot Ankle Surg., 50: 4414, 2011.

22- BROWN M.L., TANG W., PATEL A., et al.: Partial foot amputation in patients with diabetic foot ulcers. Foot Ankle Int., 33: 707-16, 2012.

23- McCALLUM R. and TAGOE M.: Transmetatarsal amputation: A case series and review of the literature. J. Aging. Res., 797218, 2012.

24- DUBSKY’ M., JIRKOVSKÁ A., BEM R., et al.: Risk factors for recurrence of diabetic foot ulcers: Prospective follow-up analysis in the Eurodiale subgroup. Int. Wound J., 10 (5): 555-61, 2013.

25- O'BRIEN P.J., COX M.W., SHORTELL C.K., et al.: Risk factors for early failure of surgical amputations: An analysis of 8,878 isolated lower extremity amputation procedures. J. Am. Coll Surg., 216: 836-44, 2013.

26- QIAN H., XU L., ZHANG S., et al.: Disease course of patients with diabetic foot ulcer during one-year followup. J. Intern. Med. Cocepts. Pract., 8 (02): 124-7, 2013.

27- HU X., SHI L. and LIU S.: Analysis of risk factors for recurrence of foot ulcer in type 2 diabetes mellitus. Today Nurse, 22 (04): 23-4, 2014.

28- CHANG X., YUAN L., WANG F., et al.: Analysis of clinical outcomes and related factors in patients with diabetic foot after discharge. Chinese Nursing Research, 31 (36): 4634-7, 2017.

29- KHALIFA W.A.: Risk factors for diabetic foot ulcer recurrence: A prospective 2 year follow-up study in Egypt. Foot (Edinb), 35: 11-5, 2018.

30- MO Z., CHEN D., GAO Y., et al.: Risk factors for foot ulcer recurrence in diabetic patients with new-onset foot ulcers. China Tropical Nedicine, 18 (07): 716-9, 2018.

31- XIE C., CHEN Y., XIONG Y., et al.: Influencing factors of recurrences of the healed diabetic foot ulcers. Chin. J.Mult. Organ Dis. Elderly, 17 (07): 501-4, 2018. 
32- HUANG Z., LI S., KOU Y., et al.: Risk factors for the recurrence of diabetic foot ulcers among diabetic patients: A meta analysis. International Wound Journal, 10: 11132, 2019.

33- ARMSTRONG D.G., BOULTON A.J.M. and BUS S.A.: Diabetic foot ulcers and their recurrence. N. Engl. J. Med., 376 (24): 2367-75, 2017.

34- DIOURI A., SLAOUI Z., CHADLI A., et al.: Incidence of factors favoring recurrent foot ulcers in diabetic patients. Ann. Endocrinol. (Paris), 63 (6 Pt 1): 491-6, 2002.

35- WAAIJMAN R., De HAART M., ARTS M.L., et al.: Risk factors for plantar foot ulcer recurrence in neuropathic diabetic patients. Diabetes Care, 37 (6): 1697-705, 2014.

36- DARLING J.D., McCALLUM J.C., SODEN P.A., et al.: system following infrapopliteal endovascular interventions for critical limb ischemia. J. Vasc. Surg., 64 (3): 616-22, 2016.

37- CONNOR H. and MAHDI O.Z.: Repetitive ulceration in neuropathic patients. Diabetes Metab. Res. Rev., 20 (1): S23-S28, 2004

38- NI P. and YUAN L.: Research Progress of influencing factors on recurrence of diabetic foot ulcer. J. Nurs. ( China), 24 (09): 35-8, 2017.

39- HUNG S.Y., TSAI J.S., YEH J.T., et al.: Amino acids and wound healing in people with limb-threatening diabetic foot ulcers. Journal of Diabetes and its Complications, 33 (10): 107403, 2019.

40- MAI L., LI Y., ZHANG L., et al.: Five year recurrence rate of ulcer in patients with new-onset diabetic foot ulcer: Risk factors. J. Nurs. Sci., 31 (11): 18-21, 2016.

\section{مخاطر حلدوث قرح وإعادة البتر بعد عمل بتر جزئى للقدم فى مريض السكرى من النوع الثانى}

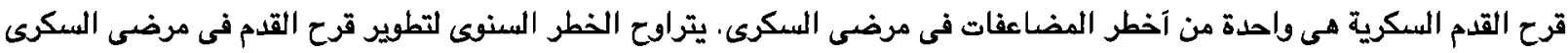

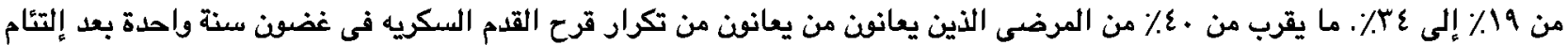
القرحة.

تنجم تقرحات القدم المتكررة عن عوامل مختلفة له آثار سلبية على الصالة الفسيولوجية للمرضى، والصحة العقلية، والآداء الإجتماعى. كان

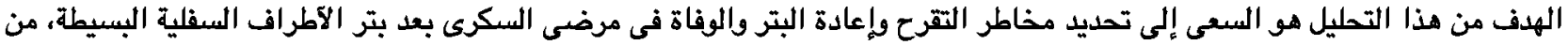

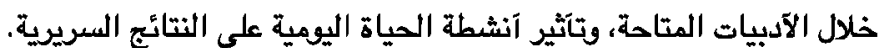

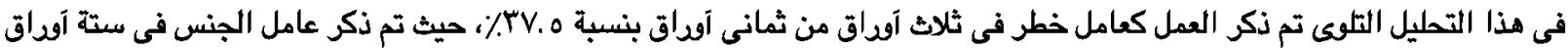

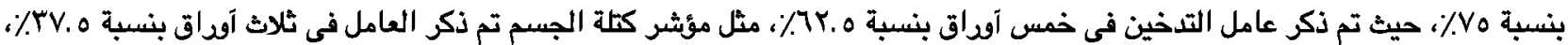

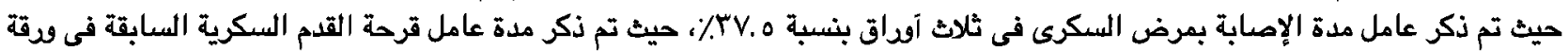

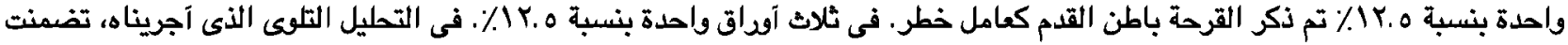

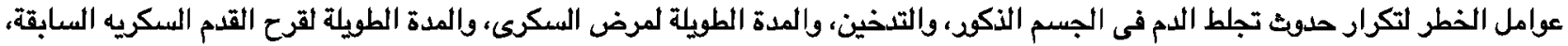

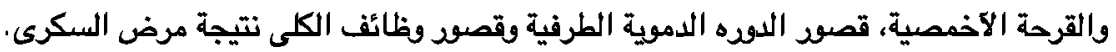

